\title{
A Study of the Attitudes of Road User using Combined Fuzzy Cognitive Maps (CFCMs)
}

\author{
A.Victor Devadoss, PhD. \\ Head and Associate Professor \\ Department of Mathematics \\ Loyola College \\ Chennai-600034
}

\begin{abstract}
Today's world is a fast moving world. As consequence it meets with more road accidents. The growing number of vehicles, population and indiscipline attitude of road users are some of the concerns for the road accidents and road congestion. In recent years the number of road accidents growing rapidly. In particular, the victims are the youth of every country. This is our main concern for taking this study. In this paper we use Combined Fuzzy Cognitive Maps (CFCMs) to study the attitudes of road users. This paper has four sections. In section one gives the Basic notation and definition. Section two describes the hidden pattern of CFCMs. Section three deals with the Description of the problem and analysis using Combined Fuzzy Cognitive Maps. In final section gives the conclusion and suggestion based on our study.
\end{abstract}

Keywords: Road Accidents, Indiscipline Attitude, Road Congestion, Combined Fuzzy Cognitive Maps.

\section{Introduction:}

Political scientist R. Axelrod [1] introduced cognitive maps for representing social scientific knowledge and describing the methods that are used for decision making in social and political systems. We have found many neuroscientists who would add lifelong learning to maintain your cognitive maps by H. Bernard Wechsler[2] Developed Nation or Under developing Nation predominantly works on upliftment of its people by making certain policies to manifest their development in Socio-Economic well being and happiness. Every Country faces problems of increase death toll by natural calamities like Earthquake, Tsunami which cannot be predicated at earliest. This paper projects towards attitude of road users on calamity of roads.

\section{Basic Definition and Notations}

Fuzzy cognitive maps (FCMs) are more applicable when the data in the first place is an unsupervised one. The FCMs work on the opinion of experts. FCMs model the world classes and causal relations between classes. FCMs are fuzzy signed directed graphs with feedback. The directed edge $\mathrm{e}_{\mathrm{ij}}$ from causal concept $\mathrm{C}_{\mathrm{i}}$ to concept $\mathrm{C}_{\mathrm{j}}$ measures how

much $\mathrm{C}_{\mathrm{i}}$ causes $\mathrm{C}_{\mathrm{j}}$. The time varying concept function $\mathrm{C}_{\mathrm{i}}(\mathrm{t})$ measures the non-negative occurrence of some fuzzy event, perhaps the strength of political sentiment, historical trend or military objective. The edges $\mathrm{e}_{\mathrm{ij}}$ take values in the fuzzy causal interval $[-1,1] . \mathrm{e}_{\mathrm{ij}}=0$ indicates no causality, $\mathrm{e}_{\mathrm{ji}}>0$

\author{
S.M.A. Shahul Hameed \\ Assistant Professor \\ Department of Mathematics, \\ AalimMuhammed Salegh College of Engineering \\ Avadi, Chennai- 600055.
}

indicates causal increase, $\mathrm{C}_{\mathrm{j}}$ increases as $\mathrm{C}_{\mathrm{i}}$ increases (or $\mathrm{C}_{\mathrm{j}}$ decreases as $\mathrm{C}_{\mathrm{i}}$ decreases). $\mathrm{e}_{\mathrm{ji}}<0$ indicates causal decrease or negative causality. $\mathrm{C}_{\mathrm{j}}$ decreases as $\mathrm{C}_{\mathrm{i}}$ increases (or $\mathrm{C}_{\mathrm{j}}$ increases as $\mathrm{C}_{\mathrm{i}}$ decreases) Simple FCMs have edges values in $\{-1,0,1\}$.

\subsection{Definition}

An FCM is a directed graph with concepts like policies, events etc. as nodes and causalities as edges. It represents causal relationship between concepts they are called as fuzzy nodes.

\subsection{Definition}

FCMs with edge weights or causalities from the set $\{-1,0$, 1\}, are called simple FCMs.

\subsection{Definition}

Consider the nodes/ concepts $\mathrm{C}_{1}, \ldots, \mathrm{C}_{\mathrm{n}}$ of the FCM.

Suppose the directed graph is drawn using edge weight $\mathrm{e}_{\mathrm{ij}} \in\{0,1,-1\}$. The matrix $\mathrm{E}$ be defined by $\mathrm{E}=\left(\mathrm{e}_{\mathrm{ij}}\right)$ where $e_{i j}$ is the weight of the directed edge $\mathrm{CC}_{i}$. E is called the adjacency matrix of the FCM, also known as the connection matrix of the FCM. It is important to note that all matrices associated with an FCM are always square matrices with diagonal entries as zero.

\subsection{Definition}

Let $\mathrm{C}_{1}, \mathrm{C}_{2}, \ldots, \mathrm{C}_{\mathrm{n}}$ be the nodes of an FCM. $\mathrm{A}=\left(\mathrm{a}_{1}, \mathrm{a}_{2}, \ldots, \mathrm{a}_{\mathrm{n}}\right)$ where $a_{i} \in\{0,1\}$. A is called the instantaneous state vector and it denotes the on-off position of the node at an instant

$a_{i}=0$ if $\underset{i}{a}$ is off and

$a_{i}=1$ if $a_{i}$ is onfor $i=1,2, \ldots, n$.

\subsection{Definition}

If the equilibrium state of a dynamical system is a unique state vector, then it is called a fixed point.

\subsection{Definition}

If the FCM settles down with a state vector repeating in the form $\mathrm{A}_{1} \rightarrow \mathrm{A}_{2} \rightarrow \ldots \rightarrow \mathrm{A}_{\mathrm{i}} \rightarrow \mathrm{A}_{1}$ then this equilibrium is called a limit cycle. 


\subsection{Definition}

Finite number of FCMs can be combined together to produce the joint effect of all the FCMs. Let $\mathrm{E}_{1}, \mathrm{E}_{2}, \ldots, \mathrm{E}_{\mathrm{p}}$ be the adjacency matrices of the FCMs with nodes $\mathrm{C}_{1}, \mathrm{C}_{2}$, $\ldots, \mathrm{C}_{\mathrm{n}}$ then the combined FCM is got by adding all the adjacency matrices $\mathrm{E}_{1}, \mathrm{E}_{2}, \ldots, \mathrm{E}_{\mathrm{p}}$. We denote the combined FCM adjacency matrix by $\mathrm{E}_{2} \mathrm{E}_{1}^{\mathrm{p}}+\mathrm{E}_{2}+\ldots+\mathrm{E}_{\mathrm{p}}$.

Suppose $A=\left(a_{1}, \ldots, a_{n}\right)$ is a vector which is passed into a dynamical system $\mathrm{E}$. Then $\mathrm{AE}=\left(\mathrm{a}_{1}, \ldots, \mathrm{a}_{\mathrm{n}}\right)$ after thresholding and updating the vector suppose we get $\left(b_{1}, \ldots\right.$ ,$\left.b_{n}\right)$ we denote that by (a', a' $\left., \ldots, a^{\prime}\right)_{n} \hookrightarrow\left(b_{1}, b_{2}, \ldots, b_{n}\right)$. Thus the symbol ' $\hookrightarrow$ ' means the resultant vector has been thresholded and updated.

Here the approach to the problem through attributes using Combined Fuzzy Cognitive Maps (CFCMs) that are basically matrices which predict the feelings of all the attributes under certain conditions.

Before we proceed to apply Combined Fuzzy Cognitive Maps (CFCMs) to this problem we define a set of ten attributes given by expert. We work with analyzing them using directed graph and its connection matrices.

\section{Description of the Hidden Path using Combined Fuzzy cognitive Maps}

\section{$A_{1}$ : Increase of Number of Vehicle}

Basically the government should try to take sincere efforts to control population explosion on meaningless reasons. We cannot expect convenient and comfortable living unless meaningful exercises are undertaken to contain population explosion and discourage rural poor migrating to urban centers causes increase of vehicle on roads.

\section{A2: Using Mobile Phones}

Usage of mobile phones while driving is common, but dangerous. Due to the number of accidents that are related to cell phone use while driving, some jurisdictions have made the use of a cell phone while driving illegal.

\section{$A_{3}$ : Noise Pollution}

Noise can cause sleep disturbance and impair people's learning, motivation and problem-solving abilities. The most irritating noise source reported to date is road traffic High level noise is a disturbance to the human environment. Because of urbanization, noise in all areas in a city has increased considerably.

\section{$A_{4}$ :Not Obeying Traffic Rules}

Every day people die on the roads due to reckless driving, speeding, spending more hours in traffic congestion causes panic, aggression, tension and stress. But as responsible citizens, it is to make the roads safer for all by simply following some basic traffic rules.

\section{A5: No Time Management}

People moving for workplace, educational institution, market place for their fulfillment of day to day needs are in state of hurry burry leads to poor time management on roads. The need to rush somewhere especially during rush hours is a symptom of poor time management.

\section{A6: Poor Road Maintenance}

The economic costs of poor road maintenance are borne primarily by road users. When a road is allowed to deteriorate from good to poor condition Far from saving money, cutting back on road maintenance increases the cost of road transport and raises the net cost to the economy as a whole.

\section{$A_{7}$ :Neglience of Pedestrains}

Negligence is known as the primary cause of many pedestrian accidents. A pedestrian will be seen as negligent if he performed a reckless action, which caused injuries to others.

\section{A8: Unprofessional Drivers}

Unprofessional drivers portray a negative image of their organizations and expose them to unnecessary risk. The possible threats are Loss of life, Damage to property. Drivers deliberately drink and drive while on wheel.

\section{A9: Encoachment of Roads}

The traffic problems are due to narrow roads mainly, If proper by pass or ring roads are built with meticulous planning ,the traffic congestion could be avoided. There are bottle necks created by lack of civic sense and encroachments by street venders and there should not be jumbling of business, education, hospital,commercial places or hotels in a single road.

\section{$A_{10}$ : Poor Maintenance of Vehicle}

According to statistics around 20 percent of all vehicle accidents are caused by auto vehicle defects. And like any kind of accident, vehicle collisions caused by auto defects result to a wide range of possible injuries. Poor vehicle maintenance is main contributor to road accidents.

Here the term 'expert' need not strictly mean an expert: it means someone who gives his views to us and has an understanding and expertise on the said subject and the related issues.

However using the fuzzy directed graph we obtain the connection matrix. Using these connection matrix we determine the hidden pattern. 


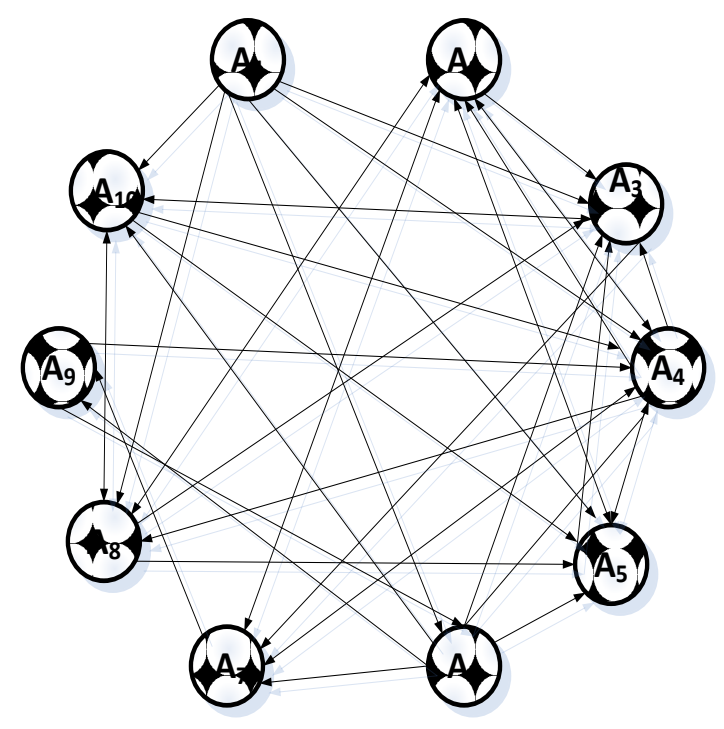

Fig:1

The related connection matrix is given by

$\mathrm{A}=\left|\begin{array}{llllllllll}0 & 0 & 1 & 1 & 1 & 1 & 0 & 1 & 0 & 1 \\ 0 & 0 & 1 & 1 & 1 & 0 & 1 & 1 & 0 & 0 \\ 0 & 0 & 0 & 0 & 0 & 0 & 1 & 0 & 0 & 1 \\ 0 & 1 & 1 & 0 & 1 & 0 & 1 & 1 & 0 & 0 \\ 0 & 1 & 1 & 1 & 0 & 0 & 0 & 0 & 0 & 0 \\ 0 & 0 & 1 & 1 & 1 & 0 & 1 & 0 & 1 & 1 \\ 0 & 1 & 0 & 1 & 0 & 0 & 0 & 0 & 1 & 0 \\ 0 & 1 & 1 & 1 & 1 & 0 & 0 & 0 & 0 & 1 \\ 0 & 0 & 0 & 1 & 0 & 1 & 0 & 0 & 0 & 0 \\ 0 & 0 & 1 & 1 & 1 & 0 & 0 & 1 & 0 & 0\end{array}\right|$

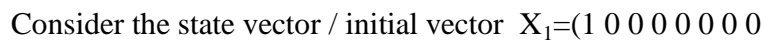
$00)$ i.e the only node 'increased number of vehicle " is only the on state and all the rest are in the off state. Now passing $\mathrm{X}_{1}$ into the connection matrix $\mathrm{A}$ we get

$$
\begin{array}{ll}
\mathrm{X}_{1} \mathrm{~A} & \hookrightarrow(0011110101)=\mathrm{X}_{2} \text { (Say) } \\
\mathrm{X}_{2} \mathrm{~A} & \hookrightarrow(0354403213) \\
& \hookrightarrow(0111101111)=\mathrm{X}_{3} \text { (Say) } \\
\mathrm{X}_{3} \mathrm{~A} & \hookrightarrow(0356413313) \\
& \hookrightarrow(0111111111)=\mathrm{X}_{4} \text { (Say) } \\
& \hookrightarrow(0467514323) \\
\mathrm{X}_{4} \mathrm{~A} & \hookrightarrow(0111111111)=\mathrm{X}_{5}=\mathrm{X}_{4}
\end{array}
$$

The hidden pattern is a fixed point which shows that increased number of vehicle makes all the other nodes to be on they are all interconnected.

As our motivation to the combined effect of the system we now for the same set of ten attributes seek the opinion of another expert. The directed graph given by the second expert is as follows

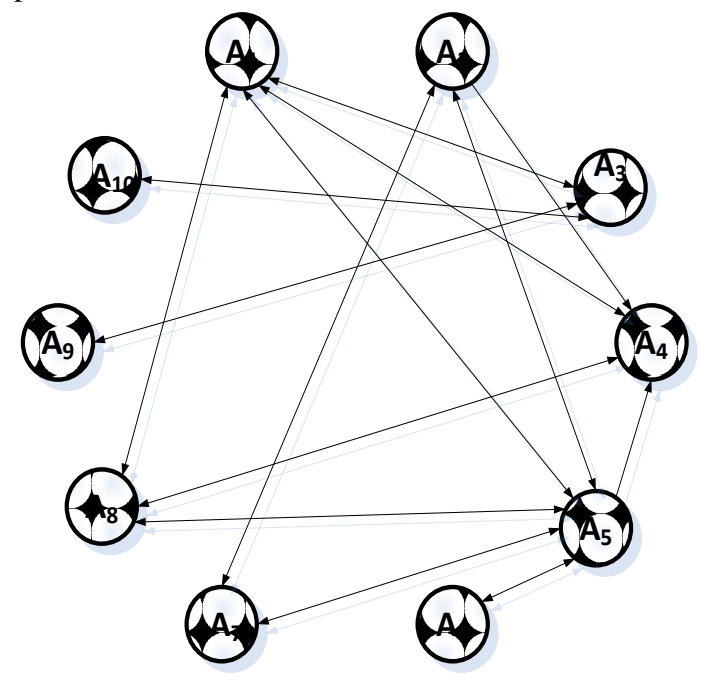

Fig:2

The related connection matrix is given by another expert

$$
\mathrm{B}=\left|\begin{array}{llllllllll}
0 & 0 & 1 & 1 & 1 & 0 & 0 & 1 & 0 & 0 \\
0 & 0 & 0 & 1 & 1 & 0 & 1 & 0 & 0 & 0 \\
1 & 0 & 0 & 0 & 0 & 0 & 0 & 0 & 1 & 1 \\
1 & 0 & 0 & 0 & 0 & 0 & 0 & 1 & 0 & 0 \\
1 & 1 & 0 & 1 & 0 & 1 & 1 & 1 & 0 & 0 \\
0 & 0 & 0 & 0 & 1 & 0 & 0 & 0 & 0 & 0 \\
0 & 1 & 0 & 0 & 1 & 0 & 0 & 0 & 0 & 0 \\
1 & 0 & 0 & 1 & 1 & 0 & 0 & 0 & 0 & 0 \\
0 & 0 & 1 & 0 & 0 & 0 & 0 & 0 & 0 & 0 \\
0 & 0 & 1 & 0 & 0 & 0 & 0 & 0 & 0 & 0
\end{array}\right|
$$

Consider the state vector / initial vector $\mathrm{Y}_{1}=\left(\begin{array}{llllllll}1 & 1 & 0 & 1 & 1 & 1 & 1 & 1\end{array}\right.$ 1 1)i.e., we take all the attributes are on except noise pollution. Now passing $\mathrm{Y}_{1}$ into the connection matrix B we get

$$
\begin{aligned}
& \mathrm{Y}_{1} \mathrm{~B} \quad \hookrightarrow \quad(3214512300) \\
& \hookrightarrow \quad\left(\begin{array}{llllllllll}
1 & 1 & 1 & 1 & 1 & 1 & 1 & 1 & 0 & 0
\end{array}\right)=\mathrm{Y}_{2} \text { (Say) } \\
& \mathrm{Y}_{2} \mathrm{~B} \quad \hookrightarrow \quad(4214512311) \\
& \hookrightarrow \quad(11111111111111)=\mathrm{Y}_{3} \text { (Say) } \\
& \mathrm{Y}_{3} \mathrm{~B} \quad \hookrightarrow \quad(4234512311) \\
& \hookrightarrow \quad(11111111111111)=\mathrm{Y}_{4}=\mathrm{Y}_{3}
\end{aligned}
$$


The hidden pattern is a fixed point which shows that increased number of vehicle makes all the other nodes to be on they are all interconnected. The directed graph given by the third expert is as follows.

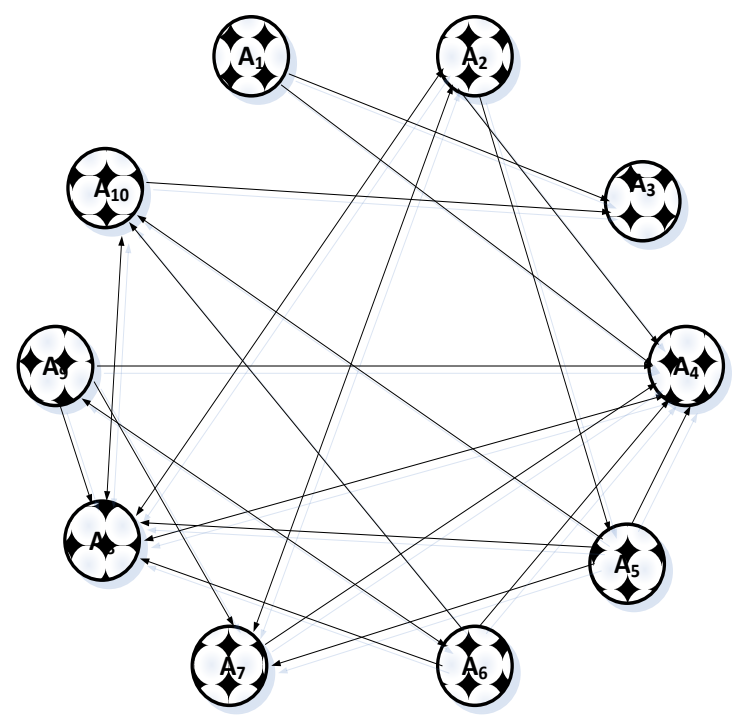

Fig.3

The related connection matrix is given by third expert

$\mathrm{C}=\left|\begin{array}{llllllllll}0 & 0 & 1 & 1 & 0 & 0 & 0 & 0 & 0 & 0 \\ 0 & 0 & 0 & 1 & 1 & 0 & 1 & 1 & 0 & 0 \\ 0 & 0 & 0 & 0 & 0 & 0 & 0 & 0 & 0 & 0 \\ 0 & 0 & 0 & 0 & 0 & 0 & 0 & 1 & 0 & 0 \\ 0 & 0 & 0 & 1 & 0 & 0 & 1 & 1 & 0 & 1 \\ 0 & 0 & 0 & 1 & 0 & 0 & 0 & 1 & 1 & 1 \\ 0 & 1 & 0 & 1 & 0 & 0 & 0 & 0 & 0 & 0 \\ 0 & 1 & 0 & 1 & 0 & 0 & 0 & 0 & 0 & 1 \\ 0 & 0 & 0 & 1 & 0 & 1 & 1 & 1 & 0 & 0 \\ 0 & 0 & 1 & 0 & 0 & 0 & 0 & 1 & 0 & 0\end{array}\right|$

Consider the state vector / initial vector

$\mathrm{Z}_{1}=\left(\begin{array}{llllllllll}0 & 1 & 0 & 1 & 0 & 0 & 1 & 1 & 0 & 1\end{array}\right)$. Now passing $Z_{1}$ into the connection matrix we get

$$
\begin{aligned}
& \mathrm{Z}_{1} \mathrm{C} \quad \hookrightarrow \quad(0213101301) \\
& \hookrightarrow \quad\left(\begin{array}{llllllllll}
0 & 1 & 1 & 1 & 1 & 0 & 1 & 1 & 0 & 1
\end{array}\right)=\mathrm{Z}_{2} \text { (Say) } \\
& \mathrm{Z}_{2} \mathrm{C} \quad \hookrightarrow \quad(0214102402)
\end{aligned}
$$

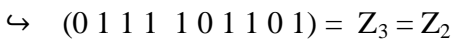

The hidden pattern is what we have obtained is the fixed point. Let us denote the combined connection matrix is $\mathrm{S}=\mathrm{A}+\mathrm{B}+\mathrm{C}$.

$S=\left|\begin{array}{llllllllll}0 & 0 & 3 & 3 & 2 & 1 & 0 & 2 & 0 & 1 \\ 0 & 0 & 1 & 3 & 3 & 0 & 3 & 2 & 0 & 0 \\ 1 & 0 & 0 & 0 & 0 & 0 & 1 & 0 & 1 & 2 \\ 1 & 1 & 1 & 9 & 1 & 0 & 1 & 3 & 0 & 0 \\ 1 & 2 & 1 & 3 & 0 & 1 & 2 & 2 & 0 & 1 \\ 0 & 0 & 1 & 2 & 2 & 0 & 1 & 1 & 2 & 2 \\ 0 & 3 & 0 & 2 & 1 & 0 & 0 & 0 & 1 & 0 \\ 1 & 2 & 1 & 3 & 2 & 0 & 0 & 0 & 0 & 1 \\ 0 & 0 & 1 & 2 & 0 & 1 & 1 & 1 & 0 & 0 \\ 0 & 0 & 3 & 1 & 1 & 0 & 0 & 2 & 0 & 0\end{array}\right|$

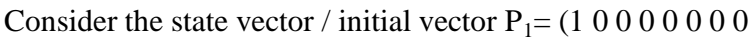
$00)$.

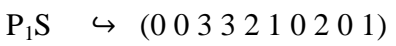

$\hookrightarrow \quad\left(\begin{array}{llllllllll}0 & 0 & 1 & 1 & 1 & 1 & 0 & 1 & 0 & 1\end{array}\right)=\mathrm{P}_{2}$ (say)

$\mathrm{P}_{2} \mathrm{~S} \quad \hookrightarrow \quad(4566315843)$

$\hookrightarrow \quad(11111111111111)=\mathrm{P}_{3}$ (say)

$\mathrm{P}_{3} \mathrm{~S} \quad \hookrightarrow \quad(48121912491347)$

$\hookrightarrow \quad\left(\begin{array}{lllllllll}1 & 1 & 1 & 1 & 1 & 1 & 1 & 1 & 1\end{array}\right)=\mathrm{P}_{4}=\mathrm{P}_{3}$

which is the fixed point for $\mathrm{S}$

\section{Conclusions and Suggestions}

\subsection{Conclusions}

The observation from our Study converges that rapid increase of vehicle growth on roads is On state makes all the rest of states to be On state. To Prevent road congestion and accident on roads the government has to take measure to control population growth reduces people moving from village to cities in search of their livelihood All kinds of accidents can be fully avoided if the general public as well as drivers with self-conscience to obey traffic rules.

\subsection{Suggestions}

To take stringent and severe action for those disobeying rules and regulations of road traffic including general public while crossing roads and also on drivers in deliberate drunken condition while on the wheel. Carrying out vehicle checks should be a part of daily driving routine Usage of mobile phones while driving to be strictly banned. Measure to be taken against encroachment of roads. 


\section{References}

[1] Axelrod. R. 1976. Structure of decision. The cognitive maps of politicalelites. Princeton University.

[2] Bernard Wechsler. H. Personality Rules Advertising, marketing, public relation Community.

[3] BartKosko. 2003. Neural Networks and Fuzzy System prentice .Hall of India private Limited. New Delhi -110001.

[4] Klir, G.J. and Folger, N.J. 1998 T.A. Fuzzy Sets Uncertainty and Information, Prentice Hall Englewood, Cliffs.

[5] W. B. Vasantha Kandasamy and Florentin Smarandache May 2004. Analysis of Social Aspects of Migrant Labourers Living with HIV /AIDS using Fuzzy theory and Neutrosophic Cognitive Mapswith Special Reference to Rural Tamilnadu in India.Published by Xiquan, Phoenix, USA

[6] W.B. VasanthaKandasamy, FlorentinSmarandache and K.Ilanthenral2007.Elementary Fuzzy Matrix Theory and Fuzzy Models for Social Scientistis.Published by Automaton. Los Angeles. USA.
[7] Wickens C.D. and Hollands J. 1999. Engineering and Psychology and human performance, Colombus , Tornoto London, Sydney; Longman 573.

[8] Nagel H.H 1994. A Vision of Vision and Language compriseAction. An Example of from Road Traffic, Artificial Inteligence Review Vol 8. pp . 189-214.

[9] Vollrath, M. and SchieB1. C. 2004. Advanced Driver Assistance of Intersections -What Do Drivers Need and want ? in AAET 2005. Automation, Assistance and Embedded Real Time Platforms for Transportation G.F.V.e.V.Editor:GZVB. Brauschweig pp.221-233.

[10] Kosko, Bart 1986. Fuzzy Cognitive Maps, International Journals of Man -Machine Studies $34,65-75$

[11] L J Sucharov et al, 1995.Effect of Driver fatigue on Truck Accident Rates, Urban Transport and the Environment for the 21st Century

[12] W J Frith, AAugust 1994. Case Control Study of Heavy Vehicle Drivers' Working Time and Safety, Proceedings of the 17th ARRB Conference 15-19 Australia. 